\section{of experimental psychology}

THIS book was compiled to mark the centenary last year of the establishment of the first laboratory in the world to be devoted exclusively to experimental psychology. Its founder was Wilhelm Wundt, a physiologist with a taste for philosophy, who had worked for many years at Heidelberg under the shadow of the great Helmholtz. After a somewhat undistinguished early career in physiology, Wundt was translated to Leipzig as a professor of philosophy, to which he was undoubtedly better suited, and at Leipzig he remained for the rest of his life.

In 1873, Wundt published the text on which his reputation has been principally based. In a later edition, this was translated into English by his devoted follower, E.B. Titchener, as Principles of Physiological Psychology. Of all Wundt's voluminous writings, this is, if not the best, certainly the best known. Wundt's own introductory statement to the original edition on "the task of physiological psychology" is one of the few extracts from his writings to appear in this volume which, however, also includes a fascinating review of the first German edition of the Principles by William James.

How did Wundt view experimental psychology? One may note first that whereas he saw physiological and experimental psychology as being virtually synonymous, he was in no doubt whatsoever that the latter warrants acceptance as a distinct and separate department of knowledge. This is well brought out in the second of the two excellent chapters by Kurt Danziger on Wundt's theoretical position. Arising from his exposition of Wundt's theory of human behaviour, Danziger directs special attention to the classical series of experiments on reaction times which were among the earliest fruits of his laboratory. Danziger treats the measurement of reaction times as in no sense a mere adjunct to physiology, as it had hitherto been viewed, but as a coherent manifestation of psychological research in its own right having direct relevance to the explanation of human behaviour.

As Wundt saw it, the most central of the issues underlying reaction time measurements was concerned with human volition. The distinction between "sensorial" and "muscular" reaction times, Wundt believed, had important theoretical implications for an understanding of volitional activity and its relationship to the evolution of higherorder choice and decision processes. Such issues, he considered, lie totally outside the
Wilhelm Wundt and the Making of a Scientific Psychology. Edited by R.W. Rieber. Pp.252. (Plenum: 1980.) £15.44, $\$ 24.50$.

province of physiology, which then even more than now was conceived to be limited to essentially reflex models of involuntary action. Indeed the prolonged neglect of Wundt's work in America was undoubtedly due, in part at least, to the protracted behaviourist hegemony and the reductionist philosophy which it embodied. Even in Germany, the belief that selective attention, so central to Wundtian thinking, lacked explanatory value, became a central tenet of Gestalt psychology and under its influence reaction times, too, ceased for many years to be of more than marginal interest.

Currently, behaviourism is clearly in decline, and cognitive and developmental preoccupations in psychology equally clearly in the ascendant. In consequence, the climate is once again more sympathetic to the Wundtian outlook and this book may itself result in a revival of interest in his work. True, concepts of information processing and control mechanisms have replaced the Wundtian concepts of volition, apperception and creative synthesis, the roots of which lie deep in the Naturphilosophie of mid-nineteenthcentury Germany. As Danziger rightly points out, present-day psychology is concerned primarily with an understanding of human performance, governed by concepts of selective attention, information processing, and decision and choice. Such a psychology may, in some sense, widen rather than diminish the gap between psychology and the neurosciences, but it leaves unaffected Wundt's insistence on experimental

\section{HBV et al.}

\section{William S. Robinson}

Hepatitis Viruses of Man. By A.J. Zuckerman and C.R. Howard. Pp.269. (Academic: 1980.) £16.80, \$39.

OCCASIONAL reviews of hepatitis viruses by experts are welcome because knowledge of these viruses has been advancing so rapidly over the past decade that it is sometimes difficult for those in the field, much less outsiders, to keep up and assimilate all of

\section{O. L. Zangwill}

psychology being conceived as an autonomous discipline which stands in symbiotic relationship with physiology. Further, although Wundt regarded social psychology as an historical and cultural rather than as an experimentally based discipline, his emphasis on its pre-eminent importance for psychology in general will find a sympathetic response in many quarters today.

One particularly valuable contribution made by this book is the challenge it provides to the received ideas about Wundt and his work which stem largely from the writings of Titchener and his pupil, E.G. Boring, the celebrated historian of experimental psychology. This challenge emerges particularly clearly in Blumenthal's chapter on Wundt and early American psychology, though it is unfortunate that it was not thought appropriate to reprint his enlightening reappraisal of Wilhelm Wundt which appeared five years ago. Danziger has also some highly relevant things to say about Titchener's many misapprehensions of Wundt's philosophical position. Solomon Diamond contributes a long essay on Wundt's early life and activities as a physiologist, though his somewhat uninhibited personal criticism may be thought to limit its biographical value.

Although inevitably a hodge-podge, this book will be welcomed by many people who are genuinely interested in the origins and development of experimental psychology, even though some of them may still continue to believe, with William James, that psychology is less a science than the hope of a science.

O.L. Zangwill is Professor of Experimental Psychology in the University of Cambridge.

the new findings. Such reviews are most helpful when they are able to provide new insights, bring some order where chaos reigns among conflicting data, evaluate new findings in the context of other relevant and better studied biological systems, or provide a bibliography which makes a body of research literature readily available to readers. The authors of this book are active investigators in the field and have a broad knowledge of recent work. They intended this book to provide "an account of the more important published advances and exciting developments in this field"'. The book does 